\title{
Performed Observation
}

National Cancer Institute

\section{Source}

National Cancer Institute. Performed Observation. NCI Thesaurus. Code C93430.

The completed action of observing, monitoring, measuring or otherwise qualitatively or quantitatively gathering data or information about one or more aspects of a subject's, study subject's or experimental unit's physiologic or psychologic state. 